\title{
Silver Nanoparticles for Hydrogen Peroxide Sensors
}

\author{
César AC Sequeira* \\ CeFEMA, Instituto Superior Técnico, Universidade de Lisboa, Portugal \\ *Corresponding author: CeFEMA, Instituto Superior Técnico, Universidade de Lisboa, Portugal
}

\begin{tabular}{|c|c|}
\hline ARTICLE INFO & ABSTRACT \\
\hline & Silver nanoparticles (AgNPs) are currently increasingly synthesized for their \\
\hline Published: 幽 December 17, 2021 & $\begin{array}{l}\text { characteristics allows the development of applications in all sensitive and essential } \\
\text { fields in the service of humans and the environment. This review aims to summarize the }\end{array}$ \\
\hline $\begin{array}{l}\text { Citation: César AC Sequeira. Silver } \\
\text { Nanoparticles for Hydrogen Peroxide } \\
\text { Sensors. Biomed J Sci \& Tech Res 40(4)- } \\
\text { 2021. BJSTR. MS.ID.006481. }\end{array}$ & $\begin{array}{l}\text { Ag NPs synthesis methods, properties, and applications in hydrogen peroxide sensors. } \\
\text { Generally, Ag NPs can be synthesized using physical, chemical, and biological routes. } \\
\text { Studies of Ag NPs have increased after clear and substantial support from governments } \\
\text { to develop nanotechnology. Ag NPs are the most widely due to their various potent } \\
\text { properties. Thus, this review discusses some different synthesis procedures and } \\
\text { hydrogen peroxide applications of Ag NPs. }\end{array}$ \\
\hline
\end{tabular}

Keywords: Silver Nanoparticles; Green Synthesis; Hydrogen Peroxide; Gas Sensors

\section{Introduction}

Silver particles have been used as antibacterial agents since the $19^{\text {th }}$ century, and now their uses have diversified to include many new physical, chemical and biological ones [1-4]. AgNPs are considered to be one of the most widespread NPs, with about 500 tons of annual global production [5]. More recently, AgNPs have been incorporated into industrial and surgical device coatings,dental coatings, and automotive smoke filters and textiles due to their effective properties against microbes [6]. The mechanism on this topic is currently under discussion by researchers [7]. In this review, relevant techniques of synthesis of metal nanoparticles will be discussed. After that, a detailed study of the properties and applications of AgNPs for hydrogen peroxide sensors will be presented.

\section{Bottom-Up and Top-Down Synthesis}

As a historical background for metal nanoparticles (MNPs), it was reported that many exploited the strengthening of ceramic matrices, including natural asbestos nanofibers, more than 4500 years ago [8]. Lead-based chemistry was pioneered in ancient Egypt for cosmetic preparation over 4000 years ago. Here, we look at a hair dye recipe using lead salts described in the text since Greco-Roman times. We report direct evidence for the shape and distribution of $\mathrm{PbS}$ nanocrystals that form in the hair during darkening [9]. Likewise, "Egyptian blue" was the first synthetic pigment prepared and used by the Egyptians using a mixture of sintered nanometer-scale glass and quartz around the $3^{\text {rd }}$ century BC [10]. Egyptian Blue represents a complex mixture of $\mathrm{CaCuSi}_{4} \mathrm{O}_{10}$ and $\mathrm{SiO}_{2}$ (both glass and quartz). In the ancient geographic regions of the Roman Empire, including Egypt, Mesopotamia, and Greece, Egyptian blue for decorative purposes has been observed during archaeological excavations.

Natural or synthetic ways can synthesize NPs by two basic approaches, including various sub-preparation methods. The first approach is called the "top to bottom" method, including breaking down bulk solid materials into smaller pieces by applying external energy from physical, chemical, and thermal techniques [11]. The second approach, called "from the bottom up, "brings together and combines atoms or molecules of gases or liquids. The top-down approach is expensive. However, it is impossible to obtain perfect surfaces and edges due to the cavities and roughness in NPs, while a bottom-up approach can get excellent results of nanoparticle synthesis. In addition, with the bottom-up approach, no waste is 
formed to be eliminated, and the smaller NPs can be obtained with better control of the sizes [12-16]. However, adapting the production of large quantities of powders on an industrial scale is not simple. A significant advantage of treatment in solution is the possibility of generating encapsulated NPs using surfactants as a protective shell, which makes it possible to obtain very homogeneous and well dispersed NPs [17].

The main bottom-up approaches are the supercritical fluid synthesis, the use of the template, the spinning, the synthesis by plasma or flame projection, the green synthesis, the sol-gel process, the laser pyrolysis, the aerosol-based process, the chemical vapor deposition, and the atomic or molecular condensation. The main top-down approaches are the mechanical milling, the etching (chemical), the electro-explosion (thermal/chemical), the spraying (kinetics), and the laser ablation (thermal). The green synthesis approach is based on biological methods (accommodating plants, algae, the mushrooms, yeasts, actinomycetes and bacteria).

\section{Types and Synthesis of Silver Nanoparticles}

Among the various types of NPs, Ag NPs have been widely developed to be utilized in various applications due to their outstanding properties. Typical applications of Ag NPs include clothing and textiles, medical devices, food storage, cosmetics, sunscreens, laundry detergents [18], bandages [19], and sensors [20]. Some studies have found that Ag NPs have cytotoxicity that can induce ROS formation in cells [21]. Therefore, many products such as detergents, toiletries, etc. In addition, their synthetic or in-use personal care, whether industrial or household, produces a release of NPs, which ultimately ends up in the sewer. This untreated wastewater affects aquatic ecosystems and thus microorganisms. Recently, Ag NPs had great concerns regarding aquatic toxicology due to the difficulty of tracking these particles in the environment and accessing their effects on living organisms [22]. The fate of NPs in the aquatic environment and their interactions, the interactions between NPs with biological and abiotic components, and their potential for damage are not well understood, and these uncertainties raise concerns about related risks. These molecules impose on humans on health and the environment [23]. Based on the Scopus database [24], the publications on Ag NPs increase with time, where it started in 1990 (two reports) and reached 7105 reports in 2020.

Colloidal Ag NPs are molecules with an average diameter of 20$40 \mathrm{~nm}$ and comprise $80 \%$ silver atoms and $20 \%$ silver ions. They are the best-selling nanoparticles ahead of carbon nanotubes and titanium nanoparticles and are released into the environment. The demand for Ag NPs has increased due to their applicability in multiple fields. Over the years, various synthesis techniques have been developed, and procedures have been improved to prepare small and uniform Ag NPs. Ag NPs were prepared by a chemical reduction technique, where the silver ions are reduced by sodium citrate [25]. As referenced, various kinds of Ag NPs have been utilized in various applications [26]. Specifically, Ag NPs of differing sizes and shapes have been used in a broad scope of uses and clinical gear, such as electronic gadgets, coatings, cleansers, swathes, etc. [27]. Explicit physical a nd optical properties of Ag NPs are subsequently essential factors in advancing their use in these applications. In such a manner, the accompanying subtleties of the materials are imperative to consider in their combination: surface property, size dissemination, clear morphology, molecule composition, dissolution rate (i.e., reactivity in arrangement and effectiveness of particle delivery), and kinds of diminishing and capping specialists utilized. The blend techniques for metal NPs are partitioned into top-down and bottom-up approaches. In these approaches which also include chemical and green methods, the electron transfer initiates the bioreduction through nicotinamide adenine dinucleotide (NADH)-dependent reductase as an electron carrier to form $\mathrm{NAD}^{+}$. The resulting electrons are obtained by $\mathrm{Ag}^{+}$ ions, which are reduced to elemental Ag NPs.

The physical technique usually utilized to prepare Ag NPs is the evaporation-condensation method. It is commonly performed using a tube furnace at atmospheric pressure, synthesizing various sizes [28]. Several attempts have been made. For instance, Tsuji, et al. [29] proposed a new method for synthesizing Ag NPs by a laser ablation technique with focused and unfocused laser beam irradiation carried out at 12 and $900 \mathrm{~mJ} \mathrm{~cm}{ }^{-2}$ intensities, respectively. The radiation wavelengths used were 355,532 , and $1064 \mathrm{~nm}$. This study revealed that the surface plasmon wavelength of Ag NPs irradiated using 355, 532, and $1064 \mathrm{~nm}$ is $400 \mathrm{~nm}$ for focused and unfocused beams. The famous chemical method for Ag NPs synthesis is a reduction by natural and inorganic reducing agents. By and large, unique reducing agents, for example, sodium citrate, ascorbate, sodium borohydride, essential hydrogen, polyol measure, Tollen's reagent, N, N-dimethylformamide (DMF), and poly (ethylene glycol)-block copolymers are utilized for the reduction of silver particles $\left(\mathrm{Ag}^{+}\right)$in aqueous or non-aqueous arrangements. These reducing agents decrease $\mathrm{Ag}^{+}$and lead to metallic silver (Ag0), trailed by agglomeration into oligomeric clusters. These clusters ultimately arrange the metallic colloidal silver particles [30]. It is critical to utilize defensive agents to stabilize dispersive NPs during metal nanoparticle planning and ensure that the NPs consumed or tied onto nanoparticle surfaces stay away from their agglomeration [31]. Green synthesis methodologies dependent on natural reducing agents rely on different reaction parameters such as solvent, temperature, pressing, and $\mathrm{pH}$ conditions (acidic, fundamental, or impartial). For the union of metal oxide nanoparticles, plant biodiversity has been extensively viewed as 
the accessibility of successful phytochemicals in different plant separates, particularly in leaves such as ketones and aldehydes flavones, amides, terpenoids, carboxylic acids, phenols, and ascorbic acids [32,33]. These parts are fit for decreasing metal salts into MNPs [34]. The fundamental focus of such nanomaterials has been researched for biomedical diagnostics, antimicrobials, catalysis, atomic detecting, optical imaging, and marking of natural frameworks.

\section{Applications of Silver Nanoparticles}

Over the last decades, the production of NPs has been increasing rapidly for applications in electronics, chemistry, biology, and almost all our daily life applications [35]. This is mainly due to their properties of being very small, close to the biomacromolecules and providing high surface area, rapid diffusion, and high reactivity in both liquid and gas phases [36,37]. Recently, Ag NPs have attracted attention in various applications such as biological, food, optoelectronics, electronic devices for energy conversion, electron field emission sources for emission displays, and surface-enhanced Raman properties [38-41]. Accordingly, utilizing Ag NPs in sensing, mainly for the excellent physico-chemical properties, will be reviewed here. Developing fast, sensitive and selective gas sensors has received great attention in environmental monitoring, national security, and food safety applications [42]. Typically, the total performance of gas sensors strongly depends on the specific area surface of the materials utilized for detection gas. Thus nano-scale sensing is predictable to display improved sensing performance [20]. Typically, semi-conductive nano metal oxides such as $\mathrm{ZnO}$ and $\mathrm{SnO}_{2}$ exhibit high sensitivity and fast responses to some gases [43] A relatively higher temperature $\left(150-600^{\circ} \mathrm{C}\right)$ required for maximum response is a big problem that restricts the practical applications in most areas [44]. Therefore, developing suitable nanomaterials to enhance the sensor response is highly recommended. Noble metal nanostructures are the most promising in this field due to LSPR. The LSPR is an optical phenomenon observed when the electromagnetic radiation excites the surface conducting electrons of MNPs, resulting in a coherent resonance oscillation of the particles. The location of the extinction maximum is highly dependent on the reflective index and dielectric properties of the surrounding environment and the adsorption of the molecules on the metal surface $[45,46]$. Therefore, the peak wavelength shift in the extinction maximum of NPs is used to fast detect moleculeinduced changes surrounding the NPs. Thus, UV-Vis spectroscopy and the naked eye can observe the changes in the absorbance of the visible and near-infrared wavelength regions.

There are many published articles on the use of LSPR sensing applications in the liquid phase to detect organic phosphorous pesticides [47] and ammonia [48]. Generally, SPR absorption of noble metal NPs is strong in the visible to near-infrared (IR) region. Moreover, SPR is particularly sensitive to its size, shape, composition, distance, and surroundings. Therefore, it displays a promising ability for various sensors. However, Ag NPs have higher extinction coefficients than gold nanoparticles (Au NPs) of the same size [49]. Due to this feature and high specific surface area, high catalytic, high crystallinity, and their electrical and optical properties, Ag NPs have been widely investigated as gas sensor applications $[41,50]$. This section will present the recent progress on Ag NPs as gas sensors for ammonia, methane, and hydrogen peroxide. Despite the wide use in industry, such as fertilizers, animal feed production, and manufacturing of paper and plastics, ammonia is a toxic material with a harmful effect on the human body as it can harm tissues and the immune system [51]. Ammonia is largely produced in deteriorating food and fruitbodies by various micro/macrofungi [52]. Thus, monitoring the concentration of ammonia in air and liquid in the atmosphere is extremely important. Recently, Ag NPs have been widely used to sense organic gases such as methane and ethanol [20,53,54]. Cannilla, et al. [55] successfully prepared Ag NPs in a poly-methacrylic acid (PMA) matrix by a photo-induced reduction process followed by deposition on a ceramic substrate to sense ammonia gas in resistive base sensors. To improve the conductivity of the thin films to be suitable for sensing, the as-prepared Ag NPs/PMA were loaded with multi-walled carbon nanotubes (MWCNTs). The developed sensor shows the considerable ability to work at low temperature with a wide range of detection range and represent fast response/ recovery times. Kumar et al. prepared face-centered cubic polyvinylpyrrolidone (PVP) capped Ag NPs at room temperature and a chemical reduction method [41]. The prepared sample showed an average size of $\sim 22 \mathrm{~nm}$, showing a conductive and metallic nature. As ammonium gas sensing, the synthesized NPs thin films showed the maximum sensitivity towards ammonia gas.

\section{Hydrogen Peroxide Sensing}

In the last decade, hydrogen peroxide $\left(\mathrm{H}_{2} \mathrm{O}_{2}\right)$ monitoring has gained importance due to its widely employed in many industrial, atomic power stations, medical sectors and its application as a disinfecting agent for water pools [56-58]. However, the high presence of $\mathrm{H}_{2} \mathrm{O}_{2}$ can cause various biological damages, leading to aging, neurodegeneration, and cancer $[59,60]$. Therefore, developing a high-response, cheap method is highly recommended for medical, pharmaceutical security, and environmental protection [59]. Various techniques, such as spectrophotometry [60,61], chemiluminescence [62], and electrochemistry [63], have been utilized to detect $\mathrm{H}_{2} \mathrm{O}_{2}$. These methods are categorized as enzymatic and non-enzymatic methods. In the case of enzymatic, the peroxidase is an illustrative enzyme for $\mathrm{H}_{2} \mathrm{O}_{2}$ exposure; however, both $\mathrm{pH}$ and temperature are limited. 
As mentioned above, noble metal NPs display strong SPR absorption with extreme sensitivity to the size, shape, composition, and surroundings suitable for colorimetric sensors in the range of visible to near-infrared region. For colorimetric assays, Ag NPs have a high ability toward the decay of $\mathrm{H}_{2} \mathrm{O}_{2}$ [64]. This reaction can mainly be sensed by colorimetric principles, as the colloidal Ag NPs exhibit a characteristic color from the LSPR. The alteration in both particle size and shape results from the incorporation of colloidal Ag NPs with $\mathrm{H}_{2} \mathrm{O}_{2}$ can be identified by determining the change in the absorption spectral at the wavelength of LSPR. For instance, Zhang, et al. [65] investigated $\mathrm{H}_{2} \mathrm{O}_{2}$ via colorimetric detection using three different morphologies of Ag NPs (triangular, spherical, and cubic). The Ag NPs with various shapes reacted with $\mathrm{H}_{2} \mathrm{O}_{2}$, and the edges of Ag NPs had been etched. The change shape transformation induced visible color change, which was used for the quantitative determination of $\mathrm{H}_{2} \mathrm{O}_{2}$. The triangular Ag NPs display the highest sensitivity for a quite small level of $\mathrm{H}_{2} \mathrm{O}_{2}(5 \mathrm{mM})$, while the cubic $\mathrm{Ag}$ NPs display lower sensitivity. Recently, Srikhao, et al. [66] prepared Ag NPs with an average particle size of $16.9 \mathrm{~nm}$ by using phenolic compound extracted from sugarcane leaves as a reducing agent. The results showed that $90^{\circ} \mathrm{C}$ and stirring for $20 \mathrm{~min}$ are the optimum conditions for phenolic compound extraction. The prepared Ag NPs were evaluated as ammonia and $\mathrm{H}_{2} \mathrm{O}_{2}$ solution sensing by UV-Vis spectrophotometer and the naked eye. It observed that the Ag NPs sensitively detect both $\mathrm{H}_{2} \mathrm{O}_{2}$ and ammonia even at low concentrations.

Moreover, the prepared Ag NPs could detect these toxic agents even after two weeks. However, measuring in spectrophotometric methods requires some standard solutions and tools such as standardized cuvettes, microwell plates, and spectroscopic equipment. To overcome these limitations, Yoshikawa et al. utilized an optical technique for detecting $\mathrm{H}_{2} \mathrm{O}_{2}$ in their work Ag NPs deposited on a glass plate/Au NPs [66]. The Ag NPs chip diffracts incident light, and the diffraction efficiency is correlated with the amount of Ag NPs. By applying a drop of $\mathrm{H}_{2} \mathrm{O}_{2}$ onto the chip, the diffraction strength debilitates due to the decay of $\mathrm{Ag}$ NPs. A movable measurement technique of the diffraction intensity changes is assembled, and the $\mathrm{H}_{2} \mathrm{O}_{2}$ detection in a concentration range of 6.7-668 mmol L-1 in about 2 min by dropping the $\mathrm{H}_{2} \mathrm{O}_{2}$ solution onto the substrate.

The electrochemical technique is promising to detect $\mathrm{H}_{2} \mathrm{O}_{2}$ due to its simplicity, lower cost, ease of operation, and high sensitivity and selectivity compared to the other techniques $[62,63]$. Many electrochemical sensors based on metals and metal oxides-based complexes have been developed to overcome the high overpotential. Due to the high electron transfer rates, high catalytic activity toward reducing $\mathrm{H}_{2} \mathrm{O}_{2}$, and significantly decreasing overpotential at oxidizing and reducing agents, Ag NPs are widely utilized to fabricate these sensors. Zhan, et al. [67] decorated Ag NPs on three-dimensional graphene (3DG) via the hydrothermal process as a sensing electrode for electrochemical detection of $\mathrm{H}_{2} \mathrm{O}_{2}$ in phosphate-buffered solutions. The electrochemical results approved that the Ag NPs-3DG based biosensor exhibits fast amperometric sensing, low LOD, wide linear responding range, and perfect selectivity for non-enzyme $\mathrm{H}_{2} \mathrm{O}_{2}$ detection. Recently, Maduraiveer, et al. [68] utilized an electrochemical sensor for $\mathrm{H}_{2} \mathrm{O}_{2}$ by using Ag NPs introduced in a silicate matrix (APS(SG). The prepared APS(SG)-Ag NPs were deposited on glassy carbon (GC) electrode. The electron transfer behavior of the APS(SG)-Ag NPs was investigated by potassium ferricyanide $\left.\left([\mathrm{FeCN})_{6}\right]^{3-}\right)$, methyl viologen (MV2) and ruthenium hexamine $\left(\left[\mathrm{Ru}\left(\mathrm{NH}_{3}\right)_{6}\right]^{3+}\right)$. The $\mathrm{GC} / \mathrm{APS}(\mathrm{SG})$ electrode displayed a twofold increase in the peak currents and fast electron transfer kinetics toward $\left[\mathrm{Fe}(\mathrm{CN})_{6}\right]^{3-}$ in comparison with the GC electrode. The GC electrode modified with APS(SG)-Ag NPs significantly improved electron transfer. The GC/ APS(SG)-Ag NP electrode as an electrocatalytic sensor against $\mathrm{H}_{2} \mathrm{O}_{2}$ offered a reduction of $\mathrm{H}_{2} \mathrm{O}_{2}$ at less negative potential and showed the experimental low detection limit of $25.0 \mu \mathrm{M}$ with the sensitivity of $0.042 \mu \mathrm{A} / \mu \mathrm{M}$. Additionally, an APS(SG)-Ag NP-based sensor showed a fast response, good stability, and reproducibility.

\section{Conclusion}

This article presented the synthesis, properties, and hydrogen peroxide applications of silver nanoparticles in a brief detail. Despite the great role of Ag NPs in sensing applications for detecting gases and vapors of some organic compounds and detecting hydrogen peroxide in industry and biosystems, the function of this effect needs more study to be fully understood. Furthermore, the longterm stability and sensitivity should be more developed by adjusting the preparation conditions, utilizing eco-friendly stabilizing agents. Moreover, recycling Ag NPs from their applications wastes is an important issue from both environmental and economic points of view. This would help in developing Ag NP based nanomaterials more safe, biocompatible, and efficient for some vital applications in our life.

\section{Conflict of Interest}

No conflict of interest with any institution/organization.

\section{References}

1. Ayesha N, Khanna T, Vohora S (1999) Silver preparations used in Indian systems of medicine: Neuropsychobehavioural effects. Indian J Pharmacol 31: 214

2. Alexander JW (2009) History of the Medical Use of Silver. Surg Infect 10: 289-292.

3. Johnson NA, Southerland MR, Youngs WJ (2017) Recent developments in the medicinal applications of silver-NHC complexes and imidazolium salts. Molecules 22: 1263. 
4. Fereshteh Jalilian AC, Sadrjavadi K, Fattahi A, Shokoohinia Y (2020) Green synthesized silver nanoparticle from Allium ampeloprasum aqueous extract: Characterization, antioxidant activities, antibacterial and cytotoxicity effects. Adv Powder Technol 31: 1323-1332.

5. Nicole C, Mueller BN (2008) Exposure Modeling of Engineered Nanoparticles in the Environment. Environ Sci Technol 42: 4447-4453.

6. Chaloupka K, Malam Y, Seifalian AM (2010) Nanosilver as a new generation of nanoproduct in biomedical applications. Trends Biotechnol 28: 580-588.

7. Prabhu S, Poulose EK (2012) Silver nanoparticles: Mechanism of antimicrobial action, synthesis, medical applications, and toxicity effects. Int Nano Lett 2: 2-10.

8. Heiligtag FJ, Niederberger M (2013) The fascinating world of nanoparticle research. Mater 16: 262-271.

9. Walter P, Welcomme E, Hallégot P, Zaluzec NJ, Deeb C, et al. et al. (2006) Early Use of PbS Nanotechnology for an Ancient Hair Dyeing Formula. Nano Lett 6: 2215-2219.

10. Johnson-McDaniel D, Barrett CA, Sharafi A, Salguero TT (2013) Nanoscience of an Ancient Pigment. J Am Chem Soc 135: 1677-1679.

11. Nabavifard S, Jalili S, Rahmati F, Vasseghian Y, Ali GAM, et al. (2020) Application of Dendrimer/Gold Nanoparticles in Cancer Therapy: A Review. J. Inorg. Organomet. Polym Mater 30: 4231-4244.

12. Iravani S (2011) Green synthesis of metal nanoparticles using plants. Green Chem 13: 2638-2650.

13. Aboelazm EAA; Ali GAM, Chong KF (2018) Cobalt oxide supercapacitor electrode recovered from spent lithium-ion battery. Chem Adv Mater 3: 67-74.

14. Fouad OA, Makhlouf SA, Ali GAM, El-Sayed AY (2011) Cobalt/silica nanocomposite via thermal calcination-reduction of gel precursors. Mater Chem Phys 128: 70-76.

15. Ali GAM, Makhlouf ASH (2021) Fundamentals of Waste Recycling for Nanomaterial Manufacturing. In Waste Recycling Technologies for Nanomaterials Manufacturing; Makhlouf ASH, Ali GAM, (Eds.); Springer International Publishing: Cham, Switzerland; Basel, Switzerland pp: 3-24.

16. Jeyaraj M, Gurunathan S, Qasim M, Kang MH, Kim JH (2019) A Comprehensive Review on the Synthesis, Characterization, and Biomedical Application of Platinum Nanoparticles. Nanomaterials 9: 1719.

17. Fouad OA, Ali GAM, El-Erian MAI, Makhlouf SA (2012) Humidity sensing properties of cobalt oxide/silica nanocomposites prepared via sol-gel and related routes. Nano 7:1250038.

18. Arora S, Jain J, Rajwade M, Paknikar KM (2008) Cellular responses induced by silver nanoparticles: In vitro studies. Toxicol Lett 179: 93 100.

19. Ma W, Yang H, Wang W, Gao P, Yao J (2011) Ethanol vapor sensing properties of triangular silver nanostructures based on localized surface plasmon resonance. Sensors 11: 8643-8653.

20. Chen X, Schluesener HJ (2008) Nanosilver: A nanoproduct in medical application. Toxicol Lett176: 1-12.

21. Farré M, Gajda-Schrantz K, Kantiani L, Barceló D (2009) Ecotoxicity and analysis of nanomaterials in the aquatic environment. Anal Bioanal Chem 393: 81-95.

22. Scown TM, Santos EM, Johnston BD, Gaiser B, Baalousha M, et al. (2010) Effects of Aqueous Exposure to Silver Nanoparticles of Different Sizes in Rainbow Trout Toxicol Sci 115: 521-534.

23. (2021) Scopus. Available online: https://www.scopus.com/(accessed on 20 august 2021).
24. Lee PC, Meisel D (1982) Adsorption and Surface-Enhanced Raman of Dyes on Silver and Gold Sols. J Phys Chem 86: 3391-3395.

25. Van Hyning DL, Zukoski CF (1998) Formation Mechanisms and Aggregation Behavior of Borohydride Reduced Silver Particles. Langmuir 14: 7034-7046.

26. Burdusel AC, Gherasim O, Mogoantă L, Ficai A, Andronescu E, et al. (2018) Biomedical Applications of Silver Nanoparticles: An Up-to-Date Overview. Nanomaterials 8: 681.

27. Chugh H, Sood D, Chandra I, Tomar V, Dhawan G, et al. (2018) Role of gold and silver nanoparticles in cancer nanomedicine. Artif Cells Nanomed Biotechnol 46: 1210-1220.

28. Tsuji T, Iryo K, Ohta $\mathrm{H}$, et al. (2000) Colloids by a Laser Ablation Technique in Solution: Influence of Laser Wavelength on the Efficiencies of Colloid Formation. Jpn J Appl Phys 39: 981-983.

29. Amendola V, Meneghettia M (2009) Laser ablation synthesis in solution and size manipulation of noble metal nanoparticles. Phys Chem Chem Phys 11: 3805-3821.

30. Oliveira MM, Ugarte D, Zanchet D, Zarbin AJG (2005) Influence of synthetic parameters on the size, structure, and stability of dodecanethiolstabilized silver nanoparticles. J Colloid Interface Sci 292: 429-435.

31. Bai J, Li Y, Du J, Wang S, Zheng J, et al. (2007) One-pot synthesis of polyacrylamide-gold nanocomposite. Mater Chem Phys 106: 412-415.

32. Jung WK, Kim SH, Koo HC, Shin S, Kim JM, et al. (2007) Antifugal Activity of the Silver Ion against Contaminated Fabric. Mycoses 50: 265-269.

33. Morales-Lozoya V, Espinoza-Gómez H, Flores-López ZL, Sotelo-Barrera EL, Núñez-Rivera A, et al. (2021) Study of the effect of the different parts of Morinda citrifolia L. (noni) on the green synthesis of silver nanoparticles and their antibacterial activity. Appl Surf Sci 537: 147855.

34. Kiani M, Rabiee N, Bagherzadeh M, Ghadiri AM, Fatahi Y, et al. (2021) Improved Green Biosynthesis of Chitosan Decorated Ag- and Co304-Nanoparticles: A Relationship Between Surface Morphology, Photocatalytic and Biomedical Applications. Nanomed Nanotechnol Biol Med 32: 102331.

35. Vanlalveni C, Lallianrawna S, Biswas A, Selvaraj M, Changmai B, et al (2021) Green synthesis of silver nanoparticles using plant extracts and their antimicrobial activities: A review of recent literature. RSC Adv 11: 2804-2837.

36. He Y, Li X, Zheng Y, Wang Z, Ma Z, et al. (2018) A green approach for synthesizing silver nanoparticles, and their antibacterial and cytotoxic activities. New J Chem 42: 2882-2888.

37. Othman AM, Elsayed MA, Al-Balakocy NG, Hassan MM, Elshafei AM (2019) Biosynthesis and characterization of silver nanoparticles induced by fungal proteins and its application in different biological activities. J Genet Eng Biotechnol 17: 1-13.

38. Kumar M, Devi P, Kumar A (2017) Structural analysis of PVP capped silver nanoparticles synthesized at room temperature for optical, electrical and gas sensing properties. J Mater Sci Mater Electron 28: 5014-5020.

39. Liu T, Rong Y, Xiong Y, Mei A, Hu Y, et al. (2017) Spacer improvement for efficient and fully printable mesoscopic perovskite solar cells. RSC Adv 7: 10118-10123.

40. Kjellander BKC, Smaal WTT, Myny K, Genoe J, Dehaene W, et al. (2013) Optimized circuit design for flexible 8-bit RFID transponders with active layer of ink-jet printed small molecule semiconductors. Org Electron 14: 768-774.

41. Park M, Im J, Shin M, Min Y, Park J, et al. (2012) Highly stretchable electric circuits from a composite material of silver nanoparticles and elastomeric fibres. Nat Nanotechnol 7: 803-809. 
42. Haverinen HM, Myllylä RA, Jabbour GE (2009) Inkjet printing of light emitting quantum dots. Appl Phys Lett 94: 073108.

43. Kala PV, Rao BT, Srinivasarao K (2019) Structural, optical and gas sensing properties of TiO2-MoO3 thin films. Int. J Thin Film Sci Technol 8: $163-174$

44. Nikolic MV, Milovanovic V, Vasiljevic ZZ, Stamenkovic Z (2020) Semiconductor Gas Sensors: Materials, Technology, Design, and Application. Sensors 20: 6694 .

45. Wan Q, Li QH, Chen YJ, Wang TH, He XL, et al. (2004) Fabrication and ethanol sensing characteristics of $\mathrm{ZnO}$ nanowire gas sensors. Appl Phys Lett 84: 3654-3656.

46. Willets KA, Van Duyne RP (2007) Localized surface plasmon resonance spectroscopy and sensing. Annu. Rev Phys Chem 58: 267-297.

47. Ghanbari R, Safaiee R, Sheikhi MH, Golshan MM, Horastani ZK (2019) Graphene Decorated with Silver Nanoparticles as a Low-Temperature Methane Gas Sensor. ACS Appl Mater Interfaces 11: 21795-21806.

48. Behera SN, Sharma M, Aneja VP, Balasubramanian R (2013) Ammonia in the atmosphere: A review on emission sources, atmospheric chemistry and deposition on terrestrial bodies. Environ. Sci Pollut Res Int 20: 8092-8131.

49. Imamura A, Yumoto T (2008) Dynamics of fruit-body production and mycorrhiza formation of ectomycorrhizal ammonia fungi in warm temperate forests in Japan. Mycoscience 49: 42-55.

50. Rahman MM, Khan SB, Jamal A, Faisal M, Asiri AM (2012) Highly sensitive methanol chemical sensor based on undoped silver oxide nanoparticles prepared by a solution method. Microchim Acta 178: 99-106.

51. Choudhury A (2009) Polyaniline/silver nanocomposites: Dielectric properties and ethanol vapour sensitivity. Sens. Actuators B Chem 138: 318-325.

52. Cannilla C, Bonura G, Frusteri F, Spadaro D, Trocino S, et al. (2014) Development of an ammonia sensor based on silver nanoparticles in a poly-methacrylic acid matrix. J Mater Chem C 2: 5778.

53. Rithesh Raj D, Prasanth S, Vineeshkumar TV, Sudarsanakumar C (2015) Ammonia sensing properties of tapered plastic optical fiber coated with silver nanoparticles/PVP/PVA hybrid. Opt Commun 340: 86-92.

54. Banihashemian SM, Hajghassem H, Nikfarjam A, Azizi Jarmoshti J, Abdul Rahman SB, et al. (2019) Room temperature ethanol sensing by green synthesized silver nanoparticle decorated SWCNT. Mater Res Express 6: 065602.

55. Martin B, Sedelmeier J, Bouisseau A, Fernandez-Rodriguez P, Haber J, et al. (2017) Toolbox study for application of hydrogen peroxide as a versatile, safe and industrially-relevant green oxidant in continuous flow mode. Green Chem 19: 1439-1448.

ISSN: 2574-1241

DOI: $10.26717 /$ BJSTR.2021.40.006481

César AC Sequeira. Biomed J Sci \& Tech Res

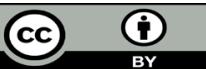

his work is licensed under Creative Commons Attribution 4.0 License

Submission Link: https://biomedres.us/submit-manuscript.php
56. Teong SP, Li X, Zhang Y (2019) Hydrogen peroxide as an oxidant in biomass-to-chemical processes of industrial interest. Green Chem 21: 5753-5780.

57. Kamrani MS, Seifpanahi-Shabani K, Seyed-Hakimi A, Ali GAM, Agarwa S, et al. (2019) Degradation of cyanide from gold processing effluent by $\mathrm{H} 2 \mathrm{O} 2, \mathrm{NaClO}$ and $\mathrm{Ca}(\mathrm{ClO})_{2}$ combined with sequential catalytic process. Bulg Chem Commun 51: 384-393.

58. Ryoo D, Xu X, Li Y, Tang JA, Zhang J, et al. (2017) Detection and Quantification of Hydrogen Peroxide in Aqueous Solutions Using Chemical Exchange Saturation Transfer. Anal Chem 89: 7758-7764.

59. Liu H, Ding Y, Yang B, Liu Z, Liu Q, et al. (2018) Colorimetric and ultrasensitive detection of $\mathrm{H}_{2} \mathrm{O}_{2}$ based on $\mathrm{Au} / \mathrm{Co}_{3} \mathrm{O}_{4}-\mathrm{CeOx}$ nanocomposites with enhanced peroxidase-like performance. Sens. Actuators B Chem 271: 336-345.

60. Teodoro KBR, Migliorini FL, Christinelli WA, Correa DS (2019) Detection of hydrogen peroxide $\left(\mathrm{H}_{2} \mathrm{O}_{2}\right)$ using a colorimetric sensor based on cellulose nanowhiskers and silver nanoparticles. Carbohydr Polym 212: 235-241.

61. Karimi A, Husain SW, Hosseini M, Azar PA, Ganjali MR (2018) Rapid and sensitive detection of hydrogen peroxide in milk by Enzyme-free electrochemiluminescence sensor based on a polypyrrole-cerium oxide nanocomposite. Sens. Actuators B Chem 271: 90-96.

62. Lee JH, Huynh-Nguyen BC, Ko E, Kim JH, Seong GH (2016) Fabrication of flexible, transparent silver nanowire electrodes for amperometric detection of hydrogen peroxide. Sens Actuators B Chem 224: 789-797.

63. Khan J, Saeed K, Khan I (2019) Nanoparticles: Properties, Applications and Toxicities. . Arab J Chem. 12: 908-931.

64. Yoshikawa H, Hieda K, Ikeda K, Tamiya E (2019) Hydrogen peroxide detection with a silver nanoparticle grating chip fabricated by plasmonic plating. Anal Methods 11: 2991-2995.

65. Zhang L, Li L (2016) Colorimetric detection of hydrogen peroxide using silver nanoparticles with three different morphologies. Anal Methods 8: 6691-6695.

66. Srikhao N, Kasemsiri P, Lorwanishpaisarn N, Okhawilai M (2021) Green synthesis of silver nanoparticles using sugarcane leaves extract for colorimetric detection of ammonia and hydrogen peroxide. Res Chem Intermed 47: 1269-1283.

67. Zhan B, Liu C, Shi H, Li C, Wang L, et al. (2014)A hydrogen peroxide electrochemical sensor based on silver nanoparticles decorated threedimensional graphene. Appl Phys Lett 104: 243704.

68. Maduraiveeran G, Kundu M, Sasidharan M (2018) Electrochemical detection of hydrogen peroxide based on silver nanoparticles via amplified electron transfer process. J Mater Sci 53: 8328-8338.

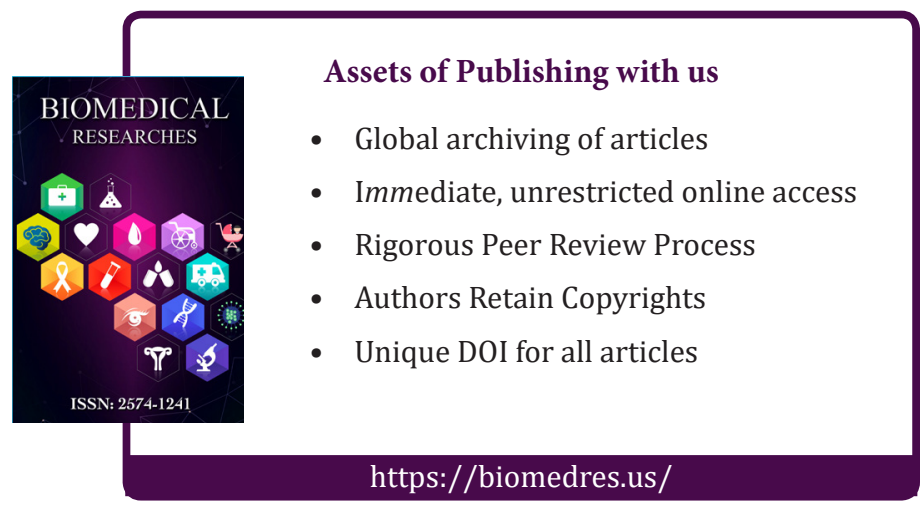

Copyright@ César AC Sequeira | Biomed J Sci \& Tech Res | BJSTR. MS.ID.006481. 